\title{
ENGENDRANDO GÊNERO NA COMPREENSÃO DAS LESÕES POR ESFORÇOS REPETITIVOS
}

\author{
Eleonora Menicucci de Oliveira* \\ Margarida Barreto**
}

\begin{abstract}
Resumo: Fruto de uma reflexão conjunta realizada pelas autoras a partir de diferentes experiências no contato com trabalhadores mulheres e homens portadores das Lesões por Esforços Repetitivos (L.E.R.s). Contatos estes, que foram possiveis pelo atendimento desses trabalhadores encaminhados pelos Centros de Referência de Saúde do Trabalhador para os serviços ambulatoriais da UNIFESP/ EPM, pelas pesquisas que as autoras estão desenvolvendo com trabalhadores do Hospital São Paulo e pela prática médica no Sindicato dos Trabalhadores nas Indústrias Químicas, Plásticas, Cosméticos e Similares de São Paulo.O fio condutor do trabalho é a incorporação da categoria gênero para compreender o impacto diferenciado das L.E.R.s na vida das mulheres e dos homens, no mundo das novas tecnologias que criam novas(os) trabalhadoras(es), novas(os) doentes e excluidas(os). Esta abordagem desvendou a esfera esquecida da subjetividade na vida desses trabalhadores. $O$ estudo apontou que adquirir L.E.R. é trazer empresa e os seus processos produtivos para o interior da casa, onde o sentimento de culpa se reforça, com implicações e interferências nas relações afetivas do cotidiano.
\end{abstract}

Palavras-chave: trabalhadores, gênero, medo, subjetividade, doença, exclusão, culpa

* Prof Dra Livre Docente do Centro de Estudos em Saúde Coletiva UNIFESP - Universidade Federal de São Paulo.

** Prof" Dr" da Faculdade de Medicina da Santa Casa de Misericórdia de São Paulo. 


\section{INTRODUÇÃO}

Este estudo é fruto de uma reflexão conjunta realizada pelas autoras a partir de diferentes experiências no contato com trabalhadoras portadoras das Lesões por Esforços Repetitivos (L.E.R.s). Contatos estes, que foram possiveis pelo atendimento das trabalhadoras encaminhadas pelo Centro de Referência de Saúde do Trabalhador para os serviços ambulatoriais da UNIFESP/ EPM, pelas pesquisas que estamos desenvolvendo com trabalhadoras homens e mulheres do Hospital Săo Paulo e pela prática médica no sindicato dos Trabalhadores nas Indústrias químicas, Plásticas, Cosméticos e similares de São Paulo.

Através destas experiências as autoras tem buscado instrumentos que possibilitem a maior compreensão sobre as Lesões por Esforços Repetitivos (L.E.R.s) e, desta maneira, contribuir para a consolidação do campo de conhecimento gênero, saúde e trabalho.

Acreditando que o conhecimento é uma prática e um esforço coletivo de diálogo entre fronteiras do saber, temos participado ao longo dos dois últimos anos, de Congressos interdisciplinares, como: $02{ }^{\circ}$ Congresso Internacional "Mujer Salud y Trabajo/Barcelona", Associação Brasileira de Estudos Populacionais - ABEP, $2^{\circ}$ Congresso Latino Americano de Sociologia do Trabalho e Seminário Internacional Gênero, Saúde e Trabalho/Universidade Federal de São Paulo( UNIFESP).

O diálogo entre os campos de conhecimentos e, no nosso caso específico, entre as ciências sociais e da saúde, tem apontado para uma leitura do processo saúde/ doença com um olhar de gênero que permite desconstruir tanto a onipotência do biológico como a do social, estabelecendo, assim, uma mediaçăo necessária entre esses dois pólos. Esta abordagem desoculta as mulheres enquanto atores do mundo do trabalho, mostrando que, como disse Elisabeth LOBO (1991) "a classe operária tem dois sexos".

As relações de gênero na produçăo do conhecimento teórico-metodológico. 
Para as pesquisadoras feministas francesas do GEDISST - Grupo de Estudos sobre a Divisão Social e Sexual do Trabalho do Centre Nacional de Recherche Scientific... a reflexão em termos de relações sociais de sexo e, ao mesmo tempo, anterior e posterior à reflexão em termos de divisão sexual do trabalho KERGOAT(1996).

O ponto chave é que ela é preexistente como noção, mas posterior como problemática. E é isto que a diferencia do uso tradicional da variável sexo (utilizado freqüentemente com uma conotação descritiva) nas pesquisas, ao ser problematizada. pelo feminismo quando mostrou que as relações de gênero não são produtos de um destino biológico, mas, antes de tudo, construções sociais que tem uma base material. Assim, elas formularam em termos de divisão sexual do trabalho um quadro que permitiu conhecer simultaneamente: a realidade e não mais os estereótipos do trabalho feminino em todos os seus aspectos e por especificar sexualmente o trabalho masculino. Um trabalho paralelo de desconstrução/reconstrução dos conceitos usualmente utilizados e de desvendar sua neutralidade mostrando as suas características sexuadas, conduzindo, necessariamente, a uma crítica dos modos de conceituação no conjunto das Ciências Sociais".

O uso do termo gênero é aqui utilizado muito além do significado puramente gramatical, para tornar-se explicativo dos atributos específicos que cada cultura impõe ao masculino e ao feminino, a partir do lugar social e cultural construído hierarquicamente como uma relação de poder entre os sexos. $O$ termo sexo reporta a um significado biológico, enquanto gênero é utilizado na perspectiva de relações e representa uma elaboração cultural sobre o sexo.

Na bibliografia básica sobre o conceito de gênero, o seu uso comporta um elenco tanto de posições teóricas, quanto de simples referências descritivas às relações entre os sexos nos afirma Scott, 1988. No seu uso mais recente parece ter aparecido entre as feministas americanas que insistiam no caráter social das distinções baseadas no sexo. Sem dúvida, a palavra indicava uma rejeição ao biologicismo determinista implícito no uso do termo sexo. 
Emerge a partir dos anos 80 e, distinguimos duas perspectivas teóricas, entre outras, que, embora não sejam excludentes apontam algumas diferenciações entre elas:

A primeira, denominada relações sociais de sexo, privilegiou no seu início a divisão social do trabalho como núcleo motor da desigualdade. O grupo expoente desta perspectiva desenvolveu diversas e importantíssimas pesquisas sobre a inserção da mulher no mercado de trabalho, a participação sindical e as mudanças tecnológicas; têm seu berço na França no grupo de pesquisadoras feministas do GDISST, tendo entre elas a filósofa brasileira Helena Hirata. O peso teórico do marxismo é muito claro dentro desta perspectiva. Recentemente, estas pesquisadoras incorporaram a noção foucaultiana de poder em suas formulações sobre as relações sociais de sexo, provocando assim, uma desconstrução paradigmática no âmbito do próprio conceito de relações de gênero, o que contribuiu enormemente para a discussão travada entre elas e DEJOURS $(1988,1993)$ sobre a construção dejourdiana da psicopatologia do trabalho (HIRATA, 1988,1993; KERGOAT, 1988,1993). Afirmam as autoras que não se pode pensar na psicopatologia do trabalho se não se considera a dimensão da sexualização do mundo do trabalho e todas as decorrências disso.

Nas pesquisas, normalmente, o uso do conceito gênero têm substituído a palavra mulher, mas é igualmente utilizado para sugerir que a informação a respeito das mulheres é necessariamente informação sobre os homens. SCOTT (1992) afirma que "... gênero é uma forma primeira de significar as relações de poder, ou melhor é um campo primeiro no seio do qual ou por meio do qual o poder é articulado..". A autora articulou dois grandes núcleos em sua definição de gênero, buscando uma conexão integral: "... o gênero é um elemento constitutivo de relações sociais baseado nas diferenças percebidas entre os sexos, e o gênero é a forma primeira de significar as relações de poder...". Assim ela nos informa que as mudanças nas relações sociais correspondem sempre à mudança nas representações de poder, sendo que a direção das mudanças não segue sempre um sentido único . 
O uso do conceito de relações de gênero têm contribuído para demolir a ambigüidade da cultura patriarcal em relação ao uso e aos valores destes dois termos, que invoca a anatomia para justificar o " destino social do gênero".

Por que estamos afirmando que as relações de gênero são construções culturais e sociais da divisão sexual? Porque gênero é a produção social e a construção cultural do sexo biológico, enquanto representação da imagem de poder relacional do homem e da mulher na sociedade.

Assim, gênero é a categoria que explica a relação de poder entre os sexos e nos dá a dimensão social da desigualdade sexual com base na naturalização e biologização dos sexos.

Creio que as abordagens paradigmáticas construidas pelas francesas não são excludentes com as de Scott, como nos diz novamente Kergoat "...é, impossivel colocar em oposição gênero e relações sociais de sexo: os dois termos são altamente polissêmicos". Encontra-se, nas duas definições, leques semelhantes de acepções que vão da variável mulheres, até uma análise em termos de relações sociais antagônicas (SCOTT, 1992; KERGOAT,1987).

Para nós o que aproxima as duas definições é o uso da dimensão relacional, que implica na conotação de reciprocidade, isto é, uma categoria só existe em relação à outra e são necessariamente relações que informam uma sociedade marcada pelas relações de poder sexualizados.

O uso da categoria gênero nos estudos e pesquisas na área da saúde no trabalho, contribui e alarga a compreensão do fenômeno do processo saúde -doença que, a partir da complexidade dos fatores que neste caso intervêm, introduz a dimensão de poder crivada pela desigualdade sexual para explicar os diferentes impactos que a exposição aos mesmos riscos químicos, ergonômicos e psíquicos nos locais de trabalho provocam 
no homem e na mulher. No caso do nosso estudo sobre a L.E.R. a categoria de género evidencia com muita clareza a diferenciação dos impactos sobre a saúde das mulheres e dos homens lesionados.

Além disso, reorganiza o conhecimento cientifico na ótica da năo desqualificação pela diferença sexual. Enfim, a aproximação da relação social como fato de cultura com a palavra sexo, sempre percebido como fenômeno da natureza," tem um efeito detonador, interrogativo, subversivo, efeito que para nós, é positivo já que pensamos que esta abordagem conduz a repensar a epistemologia das Ciências Sociais" (KERGOAT, 1996).

Na perspectiva da definição de gênero de Scott, a relação entre o trabalho e o sofrimento psicofísico sugere que as mulheres podem experimentar uma receptividade especial ao sofrimento mental que compromete imensamente a saúde, pela responsabilidade familiar, pelo assédio sexual no mundo do trabalho e pela insegurança no trabalho decorrente da dupla e ou extensiva jornada de trabalho - na casa e fora da casa.

A perspectiva das relações de gênero na interseção trabalho/ saúde deverá além de romper com a noção da centralidade da categoria trabalho como universalizante, dar conta de mais dois niveis: um que tem a ver com o processo de socialização de valores e a maneira com que estes determinam os comportamentos das mulheres em torno do cuidado da saúde e com assistência às enfermidades; 0 outro, mais macro, que tem a ver com a forma em que se determinam os espaços mais feminilizados do mercado de trabalho e que também implicariam na criação de condicionantes particulares do trabalho que afetam de maneira distinta as componentes do segmento feminino da força de trabalho.

Fazemos neste estudo uso tanto do conceito de relações sociais de sexo como de relações de gênero, porque ambos são mediados pelo poder. Estes conceitos são o princípio organizador das práticas sociais. Já nos disse KERGOAT (1987) "ele indica que 
a dimensão sexuada é parte integrante do social e deve ser levada em conta na construção das categorias de análise das ciências sociais ( trabalho de desconstrução) e indica a necessidade de forjar "instrumentos "conceituais aptos a analisar a dinâmica complexa do conjunto das relações sociais (trabalho de construção)."

O terceiro elemento contido na definição de SCOTT (1991): "...instituições e organizações sociais que exercitam este poder, isto é, uma visão mais ampla que inclua não só as relações de parentesco, mas também o mercado de trabalho, a educação e o sistema político..." o utilizamos para desvendar as relações de poder entre os gêneros no mundo do trabalho, para além das relações familiares como também analisaram as pesquisadoras francesas do GEDISST. A autora, nos diz que precisamos de uma visão mais ampla do que aquela que reduz o uso da categoria de gênero ao sistema de parentesco, fixando o seu olhar sobre a esfera doméstica e na família como fundamento da organização social. Esta visão deve incluir o mercado de trabalho, principalmente, nas sociedades modernas e complexas, como sexualmente segregado que é parte da construção das relações de gênero. Estas são relações sociais de poder construídas no parentesco, na economia, na organização política e pelo mercado de trabalho, sendo a forma primeira de significar as relações de poder.

Os condicionantes de gênero podem incidir fortemente sobre a saúde, chegando a constituir causa de deterioração em si. Algumas autoras mencionam (TORRES, 1991; OLIVEIRA, 1996), a maior incidência de vivências depressivas em mulheres em virtude dos conflitos decorrentes dos lugares de socialização. Em particular, as vivências estão relacionadas com a grande rigidez dos valores diferenciados sexualmente por uma criatividade atávica ao equilibrarem a relação tempo doméstico - tempo social.

Entendemos que o processo de trabalho é determinante na qualidade de vida das mulheres, que por sua vez se relaciona com a vida de consumo familiar - o cotidiano - e com a esfera pública. A qualidade de vida é determinada pelos processos destrutivos que são aqueles que deterioram a saúde, tanto quanto pelos processos que protegem e previnem a saúde das mulheres. 


\section{NOVAS TECNOLOGIAS: NOVAS/OS TRABALHADORAS /ES DOENTES E EXCLUÍDOS}

A L.E.R. - Lesão por Esforço Repetitivo, doença conhecida desde os tempos de Bernardino Ramazzini (1700), vem adquirindo na atualidade grande importância, por sua presença constante e progressiva nos ambientes de trabalho e em diferentes categorias e ramos de atividades, constituindo-se na mais recente epidemia (CODO, 1995; SETTIMI, 1995).

Caracterizada pelo acometimento de nervos, sinóvias, fáscias, tendões, ligamentos e músculos, em conseqüência de distúrbios funcionais ou orgânicos resultantes de fadiga localizada, tem denominações diferenciadas, como: "Repetitive Strain Injury (Austrália), Ocupation Cervicobrachial Disorder (Japão) ou Cumulative Trauma Disorders (EUA)", Sindrome de "overuse", Desordem ocupacional do pescoço e membros superiores. Entre nós, desde 1992, após seminário em São Paulo, a terminologia utilizada é LER, sendo estendida para todo território nacional após resolução publicada pelo INSS em março de 1993 (SETTIMI, 1995).

Todas estas denominações unificam caracteristicas relacionadas à doença do trabalho decorrente de:

a) Introdução de novas tecnologias, alteração na organização do trabalho, modificação do processo produtivo, tarefas fragmentadas e alta repetitividade, ritmo acelerado, polifunçăo, hierarquia e pressão, exigência de produção, sobrecarga muscular estática, jornadas prolongadas e ausência de pausas no trabalho.

b) Historia ocupacional (anamnese): referência à repetitividade da tarefa.

c) Sintomas e sinais localizados nos membros superiores e inferiores.

c) Invisibilidade laboratorial: os exames realizados, quando positivos (30\%), apontam para a gravidade da doença. 
As pesquisas têm mostrado a presença de danos à saúde em vários países desenvolvidos, relacionando-os com: alto nível de industrialização, uso de tecnologia avançada no processo produtivo e a nova forma de organização do trabalho.

No Japão, as L.E.Rs começaram a aparecer na década de 60 , em perfuradores de cartão e operadores de caixa e datilógrafos; na Austrália, a década de 70 evidencia a presença desta doença em digitadores, operadores de linha de montagem e embaladores, através do pagamento de benefícios, o mesmo ocorrendo nos Estados Unidos onde 56 $\%$ das doenças ocupacionais correspondem às Lesões por Esforços Repetitivos. $\mathrm{Na}$ Suécia, em 1990, uma pesquisa com 22.180 trabalhadores concluiu que $39 \%$ destes apresentavam cervicalgia, mostrando um aumento da patologia em relação ao ano anterior em que os achados foram de 31\% (MAEDA,1977; LINTON, 1990; COUTO, 1991; CODO, 1995; ASSUNÇÃO, 1995).

A eclosão desta patologia no cenário nacional data de 1984, com o surgimento em digitadores de empresas de processamento de dados, sendo que o seu reconhecimento como doença profissional data de 1987. A emergência da LER coincide com as mudanças observadas na organização do trabalho na indústria, no comércio e nos serviços, com a introdução de inovaçōes tecnológicas e novas formas de gestão. Associa-se à entrada do modelo de acumulação flexivel, à restruturação da produção e à terceirização.

Estas mudanças no sistema produtivo "vêm redefinindo traços culturais sedimentados, padrões de comportamento gerenciais, estruturas organizacionais e metodologias de abordagens de questões estratégicas e operacionais" (TOMEI,1996), culminando com o incremento de tarefas monótonas, repetitivas e fragmentadas, tarefas estas que associadas ao ritmo imposto pela exigência de maior produtividade em menor tempo, desencadeiam processo de sofrimento psicofísico que, na maioria das vezes, tem sido desconsiderado. 
Inicialmente diagnosticada em digitadores de empresas de processamento de dados e bancários, desde 1982, sabe-se que hoje está presente nos diferentes ramos de atividades como: usuários e usuárias de terminais de vídeo, processadores e processadoras de dados, bancários e bancárias, datilógrafos e datilógrafas; caixas de supermercados, trabalhadores e trabalhadoras de fábrica de auto peças, linha de montagem, microeletrônica, telecomunicações (ASSUNÇÃO, 1995; RIBEIRO,1995). Encontra-se também nas categorias: alimentaçăo, têxtil, metalúrgico, serviço público e privado, comércio varejista, gráfico, confecção e vestuário, comunicações, correio e telefonia (CODO, 1991; SETTIMI, 1995; SCHÜLER,1995;) cosméticos, plásticos, químicos, farmacêuticos, tinturaria e similares (BARRETO, 1995), hospitais, entidades financeiras, empreiteiras e locadoras de mão de obra, calçados (ASSUNÇÃO, 1993).

O levantamento de dados existentes na Secretaria de Saúde do Sindicato dos Trabalhadores nas Indústrias Químicas, Plásticas, Cosméticos e similares evidenciou que em 1995, dos casos de doenças ocupacionais atendidos, $42,50 \%$ correspondiam às LERs, o que representa $30,0 \%$ de todo o atendimento incluindo acidentes e doenças. Atualmente, $52,50 \%$ das doenças ocupacionais atendidas no Sindicato são LERs e, entre estas, $86,72 \%$ são mulheres, mostrando aumento em relação ao ano de 1995 , onde as mulheres representavam $75,30 \%$ dos portadores de LER. Dados semelhantes encontramos em pesquisa que realizamos com trabalhadoras/es do Setor Bancário de São Paulo, pelo Núcleo de Estudos e Pesquisas em Saúde da Mulher em Relações de Gênero da UNIFESP e em levantamentos de fontes secundárias no CEREST e Centro de Referencias em Saúde dos Trabalhadores.

Atualmente, é a doença de maior notificaçăo no pais, explicitando um "grave e complexo problema de saúde pública e social ..." (RIBEIRO,1995), em que o adoecer em consequêencia do trabalho deixa de ser fato esporádico, passando a fazer parte do dia-a dia de centenas de trabalhadores e trabalhadoras.

A nova ordem estratégica do capital, imposta a centenas de trabalhadores, tem envolvido alta rotatividade da mão de obra nas empresas. A força de trabalho no mercado 
encontra-se dicotomizada entre trabalhadores/trabalhadoras doentes, demitidos e excluídos e aqueles que, enquanto sadios estão incluídos.

\section{INTENSIFICAÇÃO DO TRABALHO X DIMINUIÇÃO DA SAÚDE: UM OLHAR DE GÊNERO.}

As mulheres têm sido as mais atingidas pela LER, variando os indices em 78,90 e $87,0 \%$ no pais (RIBEIRO, 1994; SETTIMI, 1995).

Em geral, as mulheres ocupam postos de trabalho e funções que se caracterizam pelo conteúdo da tarefa: alta repetitividade, monotonia, ritmo intenso, esforço físico, falta de criatividade associada à exigência de produtividade e pressão da chefia. Tarefas considerados para mulher, por exigir mais: delicadeza, atençăo, sensibilidade, concentração, responsabilidade, paciência, movimentos leves e tantos outros, obedecendo à dinâmica da divisão sexual do trabalho. Estas tarefas têm sido desvalorizadas ao longo dos séculos pelo fato de a capacitação obtida não passar pela "qualificação institucionalizada", isto é, as mulheres se qualificam para as tarefas que exigem maior destreza e minuciosidade no cotidiano da vida doméstica.

Vários autores correlacionam a maior incidência de LER em mulheres com fatores hormonais, caracteristicas anatômicas e morfológica, fatores da esfera psíquica como neuroses de compensação e histeria, culpa, estrutura da personalidade (RIBEIRO,1995; ALMEIDA, 1995). Estes argumentos fortalecem a desvalorizaçăo da força de trabalho feminina, acentuando as discriminações de gênero e não considerando as exigências diferenciadas impostas nas relações e organização sexual do trabalho.

Sabe-se que um dos determinantes da depressão está na organização do trabalho, explicitado na relação como a chefia, com os diferentes dispositivos de controle para homens e mulheres, com o assédio sexual no local do trabalho e as tarefas desprovidas de conteúdo. 
O uso da categoria gênero na relação saúde-trabalho tem possibilitado incorporar outras dimensões até então esquecidas no mundo do trabalho, como a sensibilidade e subjetividade que revelam, enquanto atributos, a capacidade de homens e mulheres perceberem diferentemente as agressões sociais, vindo a constituir o adoecer um grito de alerta e denúncia da relação hierárquica de poder entre os gêneros no local de trabalho. Além disso, visibiliza a diferença como um direito de cidadania e eqüidade na relação de gênero e não como uma desigualdade.

As análises dos modos de gestão taylorista e neo-taylorista, nas áreas de ergonomia, psicopatologia do trabalho, epidemiologia social vêm demonstrando a responsabilidade do modo de gerir com os danos provocados à saúde dos trabalhadores, como por exemplo: estresse, fadiga, doenças osteomusculares (LER), lombalgias, insônia, fadiga nervosa, depressão, doenças cardiovasculares, envelhecimento, úlceras, hérnias de disco entre outras.

O cansaço gerado durante e ao término da jornada é resultado do gasto energético no ato de produzir, mostrando uma atividade desumana, exaurida em suas forças. Fadiga muscular e estresse mecânico atuam nas cartilagens em conseqüência dos movimentos repetitivos, favorecendo as contrações musculares e conseqüente isquemia do tecido local.

É importante salientar que no chão da fábrica a trabalhadora tem responsabilidade além do prescrito para sua função; são tarefas complementares, extras, como por exemplo: limpar o posto de trabalho e a máquina, fazer café na falta da responsável, limpar o escritório dos chefes, enquanto os homens fazem serviço em casa do patrăo, como por exemplo: pintar portões e casa, jardinar, trabalhos de manutenção elétrica e hidráulica. Na penosidade das tarefas extras, evidenciam-se as relaçőes de gênero.

À primeira vista, estas mudanças de funções nos levam a pensar na pausa e rotatividade de tarefas tăo necessárias e que acarretariam um menor desgaste psico- 
físico nos trabalhadores e trabalhadoras. Sabemos entretanto que são tarefas impostas, geradoras de sobrecargas e impactos na qualidade de vida desses trabalhadores e dessas trabalhadoras.

Em nossa experiência, temos constatado que os homens, quando em funçöes cuja característica da tarefa é a repetitividade e intensidade de movimentos associadas à pressăo da chefia são acometidos da doença entre $15,0 \%$ a $24,0 \%$, o que do ponto de vista epidemiológico, além de confirmar os achados nacionais e internacionais, impõe o uso da categoria gênero para compreender o porquê do maior acometimento entre as mulheres.

\section{DOENÇA INVISIVEL, PARA QUEM?}

O que tem chamado mais nossa atençăo nos diferentes acompanhamentos que fazemos com trabalhadores e trabalhadoras portadores/as de LER são as questões que emergem nas discussões em grupos. Esta estratégia coletiva tem Ihes permitido socializar o sentir a doença, revelando nova forma de entender a realidade.

É importante destacar que nos grupos a presença das mulheres tem sido majoritária, mesmo porque elas săo o maior contingente atingido pela doença. As trabalhadoras conheceram o que sentiam, embora não sabendo as razões do aparecimento da doença, rompendo com a sua vivência solitária.

O traço identificatório entre elas foi o sentimento de vergonha por não conseguir dar a produção exigida; escondiam a dor, evitando expor-se às discriminações ou serem demitidas. O penoso caminho pelo qual as mulheres passam vai desde o descrédito da chefia e de colegas até às idas e vindas aos ambulatórios, na busca do diagnóstico do desconhecido, porém sentido. Há um descrédito quase generalizado por parte de profissionais da saúde, quando surgem as primeiras queixas.

Observamos em nossas experiências que as mulheres têm seu diagnöstico mais contestado e dificultado, o que as faz percorrer uma "via crucis" maior do que a dos homens para provar o que sentem. 
As mulheres citam profissionais que, sem escutar sua história ou examiná-las já passam as condutas de tratamento. Muitas delas têm que provar o nexo causal, como relatou uma trabalhadora: "Após dois anos de angustia, depressão e humilhação consegui provar aos médicos que não estava mentindo; provei pra todo mundo, pra minha família... Em muitos momentos eu já não sabia o que fazer. Pensava que estava louca: o médico não acreditava, o marido e toda minha familia achava que eu estava com manha. Fiquei abalada, me sentindo aleijada e infeliz".

Um depoimento de uma das trabalhadoras atendidas no ambulatório de Saúde do Trabalhador da UNIFESP nos chamou atenção pela intensidade com que articula a ausência de desejo sexual provocado pelo cansaço, ansiedade, tensão, ritmo das tarefas, pressão da chefia com o sofrimento psicofísico semelhantes aos sintomas de LER ."...às vezes não tenho desejo sexual por causa do cansaço, mas procuro não deixar que o trabalho me estresse tanto. Os riscos maiores no meu trabalho como operária de produção metalúrgica estão relacionados com os ritmos da produção que descontrolam meu ritmo biológico da menstruação...". Isto aponta para a necessidade de investigações mais criteriosas e não discriminatórias em relação à fala das próprias mulheres.

As mulheres resistem a toda humilhação sofrida no ambiente fabril e frente à repetição de condutas terapêuticas sem resultados, mulheres e homens conseguem ironizar, identificando o profissional como: "Dr. Voltaren, Dr. Injeção e trabalho, Dr. Gessinho e Dr. Mentira, Dr. Espanta peão, Dr. Veterinário"; são as representações sociais associadas a animais, objetos inanimados que expressam uma estratégia de resistência ao descaso do tratamento recebido.

São comuns os comentários discriminatórios por parte de encarregados, chefias, médicos e colegas, como: "LER é coisa de mulher"; "LER é doença de lerdas"; "lá vem as leréticas"; "vocês todas estão podres, estão leréticas"; "vocês não prestam pra mais nada"; "por que não casa com um homem rico e resolve seu problema pra sempre?"; "isso é só cansaço, não é nada grave, muita gente tem problema mais grave que o seu e trabalha 
normal"; "isso você pegou fazendo tricô em casa, isso se pega até na cozinha"; "só você fica doente, as outras têm mais tempo aqui e nada aconteceu"; "queria saber o que você tem com esse médico, que só lhe afasta". Estas narrativas demarcam uma realidade: as trabalhadoras e trabalhadores não inventam doença, escondem-na por medo de perder o emprego. Em decorrência destas discriminações, buscam cuidados fora da empresa, como último recurso.

Todas as trabalhadoras que participaram dos grupos apresentaram dores nos membros superiores em múltiplas localizações. Inicialmente as dores eram unilaterais, exigindo um esforço maior do outro membro para continuar executando sua rotina no ambiente de trabalho, desencadeando o aparecimento de sintomas no membro oposto. Esta situação evidencia a maior incidência bilateral das lesões e multiplicidade dos segmentos atingidos que em nossos estudos alcançaram $65,0 \%$ dos casos sendo, respectivamente, os segmentos mais comprometidos: punhos (92\%), mãos $(74,70 \%)$ e $\operatorname{dedos}(63 \%)$.

Por ser a dor o sintoma dominante e constituir-se em vivência individual, sem marcas fisicas visiveis, passa a não ser valorizada "sendo 'percebida', quando o quadro clínico se encontra em estágio já avançado, trazendo grande incômodo ou mesmo incapacidade no trabalho e nas tarefas extralaborais" (SETTIMI, 1995).

Com intensidade variável e repercussão diferenciada, a dor vai aos poucos intensificando e se associa à sensação de peso, choque, căibras, formigamentos, edema, dificuldade para realizar movimentos e diminuição da força muscular. As mãos e punhos são os mais atingidos, interferindo no cotidiano das mulheres e impossibilitando-as dos atos mais simples.

O relato das trabalhadoras nos alerta para a importância de ações preventivas na organização de trabalho e simultaneamente para tratamentos precoces em que haja a vigilância em saúde do trabalhador, dentro da empresa. Essa conduta evitaria que casos 
iniciais se transformassem em crônicos, levando à incapacidade definitiva para o trabalho e que novos casos aparecessem. Um dos depoimentos que mais expressou essa situação é o seguinte:

"Comecei a sentir dor no braço direito depois de quatro meses na funçăo de embaladora. As dores pioravam a cada dia e fui agüentando o quanto pude. Depois de um ano procurei o médico da empresa que disse ser reumatismo. Fui colocada para trabalhar no xarope, onde devia colocar o rótulo no xarope e recolocar na esteira. Ai o braço esquerdo começou a doer, começou a inchar. Voltei várias vezes ao médico e ele me engessou quatro vezes e eu sempre voltava pra fazer as mesmas coisas. Não sabia o que estava acontecendo, sabia que eram coisas estranhas. Eu pensei algumas vezes que devia ser o trabalho, mas o médico me disse que não era. Fiquei apavorada quando descobri que pra escrever uma ficha escolar de meus filhos, levava horas e até dias em conseqüência da dor. Aí fiquei com muito medo". Esta situação seguramente interfere em seu psiquismo, tornando-a tensa e ansiosa.

As experiências vivenciadas săo marcadas pelo sofrimento psicofísico. 0 descrédito na doença por parte da empresa (que năo a reconhece como doença do trabalho e não notifica), a conduta dos médicos, colegas, familiares, acentuam o sofrimento psicofísico, que é reforçado pela dor física, dificuldades diárias, afastamento da vida pública e retorno ao espaço doméstico de forma fragmentada. Os sonhos e perspectivas, a autoestima se perdem na necessidade de provar o invisível como forma de se encontrar. $A$ dor rompe com o silêncio do corpo submetido.

Em casa estão conservadas as tarefas domésticas, independente das horas trabalhadas fora. Diriamos que adquirir LER no interior da empresa é "trazer" a empresa/ processo produtivo para o interior da casa, com suas implicaçőes no cotidiano, interferindo diretamente nas relaçőes familiares. Some-se a isso as características do trabalho doméstico: longas jornadas, com início muitas vezes às 4 ou 5 horas da manhã, que se prolonga na empresa, e o retorno à casa significa "manter/recomeçar/continuar" todas as tarefas rotineiras e repetitivas, num verdadeiro entrelaçar de tempo e vida. 
O prolongamento solitário da jornada de trabalho impede o descanso. A rotina familiar é modificada. Necessita de ajuda para as minimas coisas: escovar os dentes, segurar um copo, pentear-se, escrever, abotoar uma blusa, lavar os cabelos, tomar banho, dificuldade para dormir por cima do braço ou mesmo de lado, para pegar pequenos objetos e telefonar, fazer amor. Para aquelas que têm filhos, as dificuldades dobram, com o cuidado com as crianças e a amamentação. No caso das tarefas domésticas: estender e lavar roupas ou pratos, esfregar e torcer roupa, varrer e limpar a casa, cozinhar, empurrar carrinho de mercado, segurar sacolas, carregar bolsa ou carteiras, manter os braços elevados nos ônibus ou metrô.

Inicialmente, filhos e maridos são os principais auxiliares nas tarefas da casa: cozinham, lavam, passam, estendem roupa (normalmente os filhos acompanham nas consultas). Há referência de ajuda das vizinhas diante da impossibilidade do marido e filhos menores ajudarem. Entretanto, o ajuste encontrado traz conseqüências no tempo: separações do casal, maior dependência de terceiros, piora da situação econômica. 0 marido que inicialmente ajudava nas tarefas da casa, ao longo do processo da doença vai se ausentando da colaboração e, em muitos casos, chega a duvidar da existência da doença. À medida que se acentua a doença, diminui a ajuda. A doença impõe seu ritmo: transforma a vida do indivíduo, da familia e da comunidade.

As idas e vindas a médicos/as em busca de melhoras geram desconfianças e surgem acusaçőes por parte do marido ou companheiro. O relato de uma trabalhadora traduz essa situação: "Meu marido acha que eu saio muito, acha que eu tô indo muito ao médico e năo acha isso normal. Agora eu tenho que levar comprovante que passei em médico ou sair com outra pessoa. Isso começou porque eu não consigo mais ter relação. Às vezes eu deixo, ai não consigo dormir de tanta dor nos braços. Ele vive dizendo que estou fingindo, que eu não tenho nada e que vai procurar outra mulher. Minha vida virou de cabeça pra baixo".

Com este cenário, a qualidade de vida da portadora de LER vai piorando gradativamente e desaparecem os apoios que Ihe dariam maior segurança no enfrentamento 
com a doença, como por exemplo: compreensão, carinho, solidariedade, alegria. Aumentam a tristeza, o sofrimento, a dor, a solidão, configurando um quadro de psicopatologia sexualizada do trabalho, conforme Eleonora OLIVEIRA(1996).

Os tratamentos a que foram submetidos são variados: homeopatia, terapia ocupacional, terapéutica alopatia (antidepressivos, antiinflamatórios, analgésicos, corticóides), fisioterapia (exercícios, ondas curtas, ultra-som, parafina) e cirurgia. Terapêuticas não convencionais foram relatadas como passes, reeducação postural global, acupuntura $(64,35 \%)$.

Mulheres que operaram por recomendação médica, em média $30,0 \%$ do total, poucas melhoras obtiveram. O fato de não poder realizar as tarefas rotineiras, mesmo depois de operada, trai a expectativa e a esperança desencadeando medo diante da impossibilidade de cura. Não encontramos casos de cirurgia nos homens, sendo a alopatia o tratamento instituído em $100 \%$ dos homens. Por quê condutas tão diferenciadas para a mesma doença?

Os homens portadores de LER (13,28\%) no grupo estudado, apresentam dificuldades inicialmente para aceitar uma doença dita de mulher. Depois, apareceu o receio de que essas caracteristicas os enfraqueçam diante dos colegas e chefia, colocando em cheque a sua virilidade. Suportam a dor, comprometendo o emocional. Todos referiram ter notado alteraçőes importantes no cotidiano e na familia, entretanto a divisão sexual do trabalho faz com que eles resistam a desenvolver atividades "consideradas femininas", recusando na maioria das vezes uma distribuiçăo equânime das tarefas domésticas.

Entre os diferentes grupos, somente dois homens referiram ajudar suas mulheres nas atividades básicas da casa como limpar e cozinhar. $\mathrm{O}$ cuidado e a atenção afetiva com os filhos são socialmente considerados uma responsabilidade das mulheres. 
Todos os homens referiram dificuldades no relacionamento sexual em consequêencia das dores causadas pela doença. É forte a sensação de perda do lazer como: não conseguir praticar esporte, pois o movimento dos braços e mãos no futebol, dominó ou cartas, aumenta suas dores.

A representação social da perda da masculinidade foi expressa quando eles alegaram sentirem-se diminuídos por não ter força física e pelo fato de o afastamento do trabalho incidir no orçamento familiar. Esta situação direciona os homens para atividades no setor informal, no bairro, vendendo pequenas mercadorias feitas por sua mulher, estabelecendo nova forma de inserção social.

A história da LER expressa a vivência depressiva marcada desde o nascimento pelas relações de poder entre os sexos. Não ter medo não significa a mesma coisa para um homem construído desde a tenra infância para a lógica da coragem e virilidade e para uma mulher que deverá ser frágil e dependente; portanto, esse imperativo não pode ser mobilizado da mesma maneira para o trabalho ou para a criação de dispositivos coletivos de defesa, segundo o sexo. Casais onde as mulheres não trabalhavam, após a doença do marido, elas saem a procura de emprego, reorganizando a divisão sexual no interior das familias.

A ausência de politicas públicas que minimizem a sobrecarga na vida privada, associada à relação homem/mulher, onde culturalmente reforça o papel de "tarefas domésticas/tarefas femininas" atua como fator de grande relevância nas relações gênero, saúde e trabalho, onde o adoecimento altera as relações na família, sendo mais realçadas as repercussões para as mulheres, resultantes de alterações e desgaste na unidade biopsicofisica.

Das discussões em grupos com as trabalhadoras e trabalhadores, evidenciou-se a necessidade de dar visibilidade social à doença, criando condições para alteração nas relações de trabalho, garantindo que medidas preventivas à saúde sejam tomadas, além 
de medidas de redução da exposição aos diversos fatores de riscos, quer nas condições ambientais quer na organização social e sexual do trabalho.

Nossos estudos têm reforçado a necessidade de pensar o mundo do trabalho com o olhar de gênero, uma vez que até hoje a abordagem da prevenção dos riscos à saúde da mulher trabalhadora tem sido na dimensão única e exclusiva da saúde materno infantil.

O uso da categoria gênero permite romper com este equívoco histórico existente na área da saúde, possibilitando evidenciar a esfera da subjetividade e a sexualidade como aspectos fundamentais para a manutenção da qualidade de vida e conseqüente equilibrio entre saúde e trabalho.

\section{REFERÊNCIAS BIBLIOGRÁFICAS}

ALMEIDA, M.C.C. Características emocionais determinadas da LER. In: Lesões por esforços repetitivos. São Paulo, Editora Vozes, 1995.

ASSUNÇÃO, A.Á. \& ROCHA, L.E. Agora ...até namorar fica difícil: uma historia de lesões por esforços repetitivos. In: BUSCHINELLI, T. Isto é trabalho de Gente. São Paulo, Ed. Vozes, 1993.p. 461-86.

ASSUNÇÃO, A.Á. Sistema músculo-esqueletico:lesões por esforços repetitivos(LER) In: MENDES, R. Patologia do trabalho. Săo Paulo, Editora Atheneu, 1995. p. 173212.

BAMMER, G. Review of current knowledge: musculoskeletal problems. Amsterdan, Elsevier Science Publishers, 1990.

BARRETO, M. A mulher e os acidentes de trabalho nas industrias químicas, farmacêuticas, plásticas e similares no municipio de Săo Paulo. [Trabalho apresentado no International Congress Women Work Health, Barcelona, April, 1996.].

BORSOI, I.C.F. A saúde da mulher trabalhadora. In: CODO, W. \& SAMPAIO, J.J.C. Sofrimentos psiquicos nas organizações. Petrópolis, Vozes, 1995. p.115-26. 
BRANDIMILHER, P.A. Condições de trabalho nos bancos: fiscalizar ou negociar? In: O mundo do Trabalho. São Paulo, Edição 46. Editora Oboré, 1996.

BUSCHINELLI, J.T.P.; ROCHA L.E.; RIGOTTO, R.M. Isto é trabalho de gente? Vida, doença e trabalho no Brasil. São Paulo, Editora Vozes, 1993.

CASTORIADIS, C. A instituição imaginária da sociedade. Rio de Janeiro, Paz e Terra, 1992. p.122-33; p.211-6.

CHANLAT, J.F. Modos de gestão, saúde e segurança no trabalho. In: DAVELE; VASCONCELOS, J. Recursos humanos e subjetividade. Petrópolis, Vozes, 1996.

CODO, W. Entre a urgência e o pasmo. In: L.E.R.: diagnostico, tratamento e prevenção. São Paulo, Editora Vozes, 1995.

COUTO, H.A. Tenossinovite e outras lesões por traumas cumulativos nos membros superiores de origem ocupacional. Belo Horizonte, Ergo, 1991.

DEJOURS, C. Souffrance et plaisir au travail: I'approche parla psychopathologie du travail in plaisir et souffrance dans le travail. Paris, Edition de l'AOCIP, 1988 / 1993. p.150174.

HIRATA, H. Psychopathologie du travail et division sexuelle: convergences er differences, in Plaisir et souffrance dans le travail. Paris, C.Edition de l'AOCIP, Tome II, 19881993. p.16-20.

KERGOAT, D. Em defesa de uma sociologia das relaçőes sociais: da análise crítica da categorias dominantes à elaboraçăo de uma nova conceituaçăo. In: O Sexo do Trabalho. Rio de Janeiro, Paz e Terra, 1987. p.69-94.

KERGOAT, D. - Relações sociais de sexo e divisão sexual do trabalho. In: LOPES,L.M.J.;Meyer.E.D.;Waldow.R.V. Gênero \& saúde. Porto Alegre, Ed. Artes Médicas, 1996. p. 19-27.

KERGOAT, D. La psychopathologie du travail dans son approche de la souffrance et du plaisir au travail, peut-elle faire l'economie des rapports sociaux de sexe? Quelques exemples precis, in plaisir et souffrance dans le travail. Paris, Edition de l'AOCIP, 1988/1993. p.161.

KURPPA, $\mathrm{K}$; et al. Incidence of tenosynovitis or peritendinitis and epicondylites in a meat processing factory. Scand J. Environ Health, 17:32-37, 1991.

LINTON, S.J. Risk factors for neck and back pain In a working population in Sweden. Work stress, 4:41-9, 1990. 
LOBO,S.E. A classe operária tem dois sexos: trabalho, dominação e resistência. São Paulo, Brasiliense/Secretaria Municipal de Cultura, 1991.

MAEDA, K; HORIGUSHI, S; HOSOKAWA,M. History of studies on occupational cervicobrachial disorder in Japan and remaining problems. J. Human Erg.11:29, 1982.

MINAYO, M.C.S. O desafio do conhecimento. Rio de Janeiro, Hucitec, 1992.

MINISTÉRIO DA PREVIDÉNCIA SOCIAL L.E.R. Lesões por esforços repetitivos: normas técnicas para avaliação da Incapacidade. Brasília, 1993.

OLIVEIRA, M.E. Psicopatologia sexualizada do trabalho: a reconstrução de um conceito.São Paulo, 1996. [Tese de Livre Docencia - Faculdade de Saúde Pública da U.S.P.].

OLIVEIRA, M.E.; CARNEIRO, F.; STORTE, R. Gênero saúde trabalho: a dimensão oculta. São Paulo. Ed. Sindicato dos Bancários SP e Brasiliense, 1996. p.15-30.

RIBEIRO, H.P. Estado atual das Lesões por Esforços Repetitivos (LER) no Banco do Estado de São Paulo S.A.-Banespa. Cad. Saúde/AFUBESP, 1:9-5, 1995.

SCOTT, J História das mulheres. In: BURKE, P., org. A escrita da história: novas perspectivas. São Paulo, Editora Unesp, 1992. p.63-96.

SCOTT, J. Gênero uma categoria útil de analise histórica. In: Gender and the politics of history. New York, Columbia University Press, 1988, tradução Brasileira-SOS-Corpo Recife, 1991. p.5-6 e 14-17.

SETTIMI, M.M. Lesőes por esforços repetitivos(LER): um problema da sociedade brasileira. In: CODO, W. L.E.R.: diagnostico, tratamento e prevenção. São Paulo, Editora Vozes, 1995. p.321-51.

SHÜLER, O. Temas de ciências sociais. In: VIEIRA,S.I. Medicina básica do trabalho. Curitiba, Gênesis, 1995. p.494-506.

TOMEI, P. A. Trabalhadores descartáveis ou recicláveis? In: DAVE, I.E; VASCONCELOS, J. org. Recursos humanos e subjetividade. Petrópolis, Vozes, 1995. p. 129-38.

TORRES, C. Gênero, salud y trabajo. Geneva, OMS, 1991. p.3-12. [mimeografado]. 
Summary: This study is the result of a joint reflection by the authors starting from different experiences of contact with women and men workers suffering of RSI. These contacts were made possible by the attendance of these workers forwarded by the Centros de Referência de Saúde do Trabalhador (Worker's Health Reference Centers) to the out-patient services of UNIFESP/EPM, by the authors ongoing research with women and men workers of Hospital São Paulo and by the medical practice of the Chemical, Plastic, Cosmetics and Similar Industry Workers Union of the State of São Paulo. The guiding thread of the work is the inclusion of the category of gender to understand the different impacts of RSI in the lives of women and men in the world of the new technologies that create new workers, new diseases and new excluded people.This approach has revealed the forgotten field of subjectivity in the lives of these workers. The study pointed out that to acquiring $\mathrm{RSI}$ is bringing the company and its productive processes into the home, where the feelings of guilt are reinforced, with implications and interferences in the daily affective relationships.

Key words: workers, gender, fear, subjectivity, disease, exclusion, guilt 